Luis C. Fuentealba Weber

\title{
Comte y el problema de la realidad
}

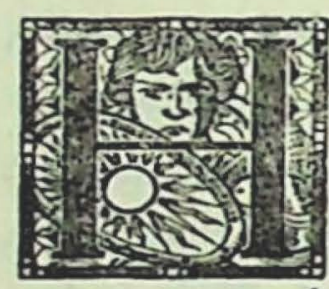

ACE justamente cien años que Augusto Comte murí́. La obra del padre del positivismo ha experimentado las vicisitudes propias del itinerario de las ideas. Muchas han sido superadas. Otras han caído en el olvido. La gran mayoría sólo reconocen el recuerdo de los estudiosos de la historia de la filosofía o de la historia de la sociología. Sin embargo nadie podrá poner en duda las contribuciones que ha dado a las ciencias y a la filosofía. En el presente artículo se intenta evocar y revivir, como un homenaje a su memoria, algunos de los pensamientos básicos que animan el sistema positivo vistos a la luz de la perspectiva actual.

Ha transcurrido mucho tiempo desde el momento en que allá en la lejana Grecia clásica surgiera la filosofía como un sistema autónomo. Nació - acaso inconscientemente- como un esfuerzo por encontrar una explicación plausible a la realidad circundante y como el deseo de escapar a las enseñanzas e interpretaciones míticoreligiosas que ya no satisfacían a la razón. Con ello el hombre se dio cuenta, por primera vez, que poseía una fuerza - el logos- que le capacitaba no sólo para introducir cambios en el mundo, sino que además - lo que es más importante- le permitía intentar el conocimiento de ese mismo mundo, ajeno a toda presión de tipo coercitivo. Esto significaba abandonar una tradición forjada por múltiples genera- 
ciones al través de milenios cuya cuenta nadie llevaba. Era el despertar de algo nuevo; de algo inusitado. Era el romper con las ideas fundamentales que guiaban a toda una cultura, para reemplazarlas en las mentes individuales por pensamientos y creencias, cuya validez se hacía descansar en argumentos que podían ser analizados y que eran la resultante de generalizaciones, que de alguna manera descansaban en la observación de la realidad captada o dada por la percepción. El hombre se había percatado que era posible entender y aprehender el mundo sensible en esquemas racionales que hacían fácil su comprensión y que autorizaban la ubicación de los objetos en una ordenación plenamente consciente. El camino y la ruta de la filosofía y de las ciencias quedaban así trazados.

Tiene el filósofo la rara virtud de descubrir problemas donde el resto de la humanidad no encuentra sino un fluir de hechos y de acontecimientos que se suceden normalmente y que calzan dentro. de fórmulas tradicionales. Colocado en el mundo de los fenómenos, sabe apartarse de ellos para mirarlos desde lejos en forma abarcadora y global. El panorama que se le presenta pierde precisión en lo que se refiere al detalle, a la catalogación minuciosa; pero gana en vuelo, en amplitud. Lo pequeño parece adecuarse y encajar en moldes más y más generales y el devenir adquiere sentido. Las cosas, los hombres, los objetos en general, pasan a tener una razón que justifica su existencia. Se ha intuido el "por qué" y el "para qué" del ser. Se ha logrado comprender qué son las cosas y hacia dónde caminan. Es en ese alejarse, en ese apartarse en que los objetos devienen problemáticos, pues cobran un matiz, un ángulo y una perspectiva nuevos, pero al mismo tiempo surgen las soluciones que los hacen caber dentro de la totalidad. De esta manera la filosofía no sólo plantea los problemas, sino que indica las direcciones generales que han de seguirse para encontrarles solución adecuada.

Gran número de las ideas que dominan en el ámbito de las ciencins fueron ya expresadas por los filósofos presocráticos. Los investigadores que después vinieron, no pudieron o no supieron apartarse de las líneas directrices que habían sido intuidas por el grupo de genios 
inmortales de la vieja Grecia. Nadie que esté interiorizado en la historia del pensamiento filosófico y científico osaría discutir la importancia y las proyecciones que han tenido en las ciencias modernas muchas de las teorías metafísicas que aparecieron en dicha época.

No se trata de efectuar un balance de los aportes que hicieron, ni siquiera de referirse a aquellas ideas que posteriormente originaron una trayectoria que se fue depurando más y más a medida que los hombres de ciencias se enfrentaban con la realidad. Ello rebalsaría las limitaciones de este ensayo e incidiría en campos que corresponden más bien a la historia de la cultura. Sin embargo, se estima útil indicar dos aspectos de la problemática filosófica que tuvieron importancia en el futuro de las ciencias. Uno apunta a las explicaciones que dieron de la realidad que hoy día se denomina físicoquímica y, el otro, a las soluciones que intentaron con respecto a los problemas de la convivencia humana, al problema de la política, esto es, de la realidad social.

El mundo de la realidad física, en sentido amplio, fue propuesto como problema por los filósofos presocráticos. Es indiscutible que las respuestas que ensayaron carecen de la confrontación con la realidad fenoménica. Las soluciones y los sistemas surgieron a base de principios racionales generales que, a pesar de estar implícitos en el espíritu humano, no habían sido aprovechados en la especulación racional hasta entonces. Se iniciaron las explicaciones empleando el principio de causalidad y suponiendo tácitamente la existencia del principio del determinismo. Aparecen los conceptos de fuerza y acaso el de ley. El uso y la aplicación que de estos principios y de estos conceptos hicieron es discutible e incierto, pero la idea de dar una interpretación válida ante la razón de lo que acontece y de lo que es, ya ha brotado. Se advierten diferencias fundamentales en las concepciones que tienen de las subtancias últimas o de las explicaciones del por qué existen los hechos; mas lo que posee importancia decisiva es que dichos principios y conceptos van a ser operantes en todo el pensamiento occidental: especialmente el principio de causalidad. También se hace presente la suposición de que la realidad percibida 
no es tal como se capta y que, por tanto, debe haber otra realidad: la auténtica, que ha de ser conocida en su esencia última. Había nacido la teoría de la existencia de los dos mundos que implica una distinción entre el mundo de esencias últimas, cuyo conocimiento es suficiente y necesario para la interpretación del mundo aparente cogido por los órganos de los sentidos. Y téngase presente que en el pensamiento contemporáneo esta diferenciación se encuentra reproducida - con otra significación- en el realismo crítico: una cosa es el objeto percibido y otra es la construcción racional-sensorial que se elabora y que apunta al objeto que está fuera de la conciencia.

Con Platón aparece un nuevo sistema de problemas: los sociales. La sociedad se convierte en problemática. Posee realidad, pero es, desde luego, distinta a la de los fenómenos físicos. Es un hecho, es también un fenómeno, una cosa, como va a decir posteriormente Durkheim. Como filósofo, Platón, se da cuenta que el estado griego, la polis, corre hacia un fin cierto y aciago. Ve que es necesario salvarlo y elabora un plan. Es tal la urgencia del problema político, que tal vez todo su sistema filosófico no sea sino el esfuerzo por establecer y justificar una constitución que diese a cada ciudadano la oportunidad de encontrar el lugar que le corresponde dentro del grupo social y un esquema educacional que le permitiese llegar a convertirse en un miembro del estado, de tal manera que hubiese una identificación entre ambos.

La ciencia se origina en el intento de explicación racional que significó la meditación filosófica. Probablemente radique aquí la razón por la cual -como se hiciera presente más arriba- no haya podido en el pasado, ni tampoco haya logrado en la actualidad escapar al influjo de la filosofía. Fue la visión generalizadora, ámbito de lo filosófico, la que le trazó los rumbos a la visión especializada de la ciencia. La física no ha podido desentenderse de las ideas rectoras de un Demócrito. Pero el advenimiento de la ciencia representa un vuelco en el enfoque del suceder. El hombre cayó en la cuenta que era necesario preocuparse del detalle, de lo pequeño, de lo parcial, si es que pretendía conocer las leyes de la naturaleza y, como con- 
secuencia, dominarla. Había aprendido que era preciso acercarse a los fenómenos y que, lo que había sido mirado desde lejos como un todo para buscar en él su propio destino, debía ser observado ahora de cerca para aprehenderlo en su encadenamiento mismo y fijarle así a la vida rutas plenamente conscientes.

El pensar filosófico que se interesó y se preocupó preferentemente por la realidad físico-química dio origen a la física en el mismo momento en el cual Galileo observó que la simple intuición sensibleracional de los fenómenos debía ser substituida por la interpretación racionalmente elaborada. Desde ese instante se desarrolló la marcha de la mecánica clásica, cuyos hitos principales son Huygens y Newton, quienes buscaron explicaciones que descansaban en principios relativamente simples.

Pero si la física había alcanzado en la investigación de los fenómenos un avance impresionante hasta el siglo XIX, la realidad social, el fenómeno social sólo había sido objeto de la reflexión filosófica. Por cierto que la filosofía social había perdido gran parte del acento puramente especulativo con pensadores como Vico, Berkeley, Ranke, Guizot y Saint-Simon. Tampoco es posible olvidar la evolución alcanzada por algunas ciencias sociales como la antropometría, la arqueología, la etnología y la economía en las cuales se destacan nombres como Bastián, Guizot, Rau entre otros. Sin embargo, y a pesar de que flotaba en el ámbito del pensamiento la idea, acaso el deseo de erigir una ciencia de lo social, hubo la necesidad de que apareciese el hombre capaz de coger los impulsos conscientes y subconscientes para sistematizarlos en una síntesis que los encaminase hacia una meta que no podía ser otra que la ciencia de los fenómenos sociales. Este hombre fue Augusto Comte (1798-1857).

El pensamiento de Comte es vertiginoso y organizador. Da la impresión - así mirado a la distancia- que absorbió en un movimiento de vórtice las ideas que venían de Condorcet, de Montesquicu y de Saint-Simon, para entregarlas en la forma ordenada, esquematizada y creadora que su razón fría le dictaba. Y no era ajeno a ello su personalidad, en que se conjugan lo melancólico, lo racional y aun 
lo patológico, y que recorre, en los aspectos afectivos, los caminos del amor que es instinto y acaso grosero, hasta el amor por Clotilde de Vaux que es tierno sentimiento de adolescente en cuerpo que la madurez ya ha golpeado.

Se desliza su vida jalonada de trabajo y de pesar, de publicaciones y de ensueños de progreso para la humanidad, como un eslabón más en la larga cadena de los pensadores que habían buscado y seguirían buscando para el hombre el sentido de la felicidad. Quiere llegar a desentrañar la naturaleza social del hombre para proporcionarle, a base del conocimiento adquirido, un futuro mejor. Hasta entonces la ubicación del hombre dentro de lo social se había ensayado como una interpretación filosófica a través de la moral o de la política, mas Comte acudirá al respaldo de las ciencias. No significa esto que abandone la filosofía. Por el contrario es, ante todo, filósofo. Y no puede llamar la atención el que un filósofo se acerque a la ciencia para interrogar al mundo como ya había ocurrido en Kant, pues el sino de la filosofía, al través de su historia, es el de apoyarse ora en la religión, ora en la ciencia, buscando con ellas o a pesar de ellas respuesta a las interrogantes que queman en el espíritu del pensador: ¿qué es la existencia? ¿qué es la esencia? En una palabra, el secreto mismo de la realidad: ¿qué es real? $\mathrm{Y}$ este es el problema fundamental, decisivo para la filosofía: ¿qué se ha de entender por realidad? Desde que los griegos, en genial visión, intuyeron y plantearon esta cuestión, hasta los días que corren, ningún pensador profundo ha podido desentenderse de él. Tampoco Comte. Su respuesta es conocida. Lo que existe es el fenómeno. La esencia de la realidad la constituye el hecho, el fenómeno. Todo lo demás es ilusión o, por lo menos, objeto que de ninguna manera puede ser conocido por cuanto no es.

El desarrollo de las ciencias físico-químicas y de la biología había enseñado que la explicación de los hechos sólo era posible si el acontecer se enfocaba desde el punto de vista de la observación y de la experimentación. La meta que se aspiraba alcanzar eran las leyes. Imperaba la confianza en el determinismo absoluto y en el principio 
de causalidad. Se había hecho evidente la idea de que sólo era posible una interpretación válida del mundo: aquella que generalizaba los hechos de una misma especie mirándolos desde el ángulo de la geometría y de las matemáticas en general. El cosmos se había convertido así en el campo donde los fenómenos podían preverse a base de los conocimientos adquiridos previamente. Ninguno podía ocurrir al acaso, por mero capricho. Si es que el mundo había sido construido o creado por una Instancia Superior, ésta tenía espíritu de físico.

Comte, inteligencia de síntesis, no podía escapar a la influencia de este desarrollo del pensamiento que dominaba la época. Veía con claridad que la única manera de llegar al conocimiento de los hechos era atacándolos con el método científico, vale decir, con la observación, la experimentación, la comparación, el cálculo. Era circunscribir la realidad a lo fenoménico en que sólo cabía un tipo de saber: aquel que se adquiere al través del método inductivo como lo había preconizado centurias antes Bacon.

Pero no en vano el hombre había reflexionado durante largos siglos en forma crítica. El ámbito donde opera la ciencia se había bifurcado. Había la realidad del mundo de los fenómenos físicos, de los fenómenos que no se refieren al hombre y que constituyen el noyo y había también la realidad del hombre, del yo. Pero mientras el macrocosmos había sido y era objeto de la indagación científica, éste era examinado exclusivamente a través de la meditación filosófica. Se le intentaba captar en el fluir hacia un destino oscuro y desconocido que estaba preñado de dioses, de ideas trascendentes, de religión, de metafísica. Era imprescindible sacarlo de allí y colocarle como un ser más entre los seres; era necesario hacer de él un fenómeno más entre los fenómenos. La idea se había gestado hacía largo tiempo y estaba grávida, pronta a dar su fruto.

Y Comte la hace germinar. El hombre existe, pero existe únicamente en cuanto es función del grupo. Es, pero es un ente social. Su existencia y su anhelo de felicidad sólo pueden encontrar vigencia dentro del grupo. Hay que estudiar, por lo tanto, el grupo, la socie- 
dad, pero en forma científica. Es preciso hacer la ciencia de lo social. Mas el término ciencia toma ahora un sentido que es nuevo. La ciencia no es sólo un sistema de conocimientos, sino que es conocimiento para prever. La verdad no puede tener un fin en sí misma, tiene que mirar hacia la posibilidad de obtener aplicaciones útiles. Cuando Comte afirma que las ciencias deben tener como fin el propender al mejoramiento o al progreso del hombre y que se ha de apreciar o medir el valor de un conocimiento, no en cuanto a la verdad en sí, sino en cuanto significa obtención de utilidad, en cuanto sea posible alcanzar una aplicación práctica y provechosa de él, no niega el concepto de verdad. Lo acepta, pero lo subordina a dos factores que, en el fondo, se entrecruzan y se unen: la previsión y la aplicación. De esta manera el sabor de pragmatismo que parecía desprenderse de esta posición gnoseológica, desaparece. Hay la verdad, mas ella ha de tener una función superior: el que sea operante.

No es tarea sencilla descubrir la razón exacta del porqué de esta posición. Sin embargo, para entenderla se ha de tener presente que Comte era ante todo un filósofo capaz de captar la problemática de su tiempo. Se había percatado que la sociedad de Francia estaba enferma a pesar de la gran revolución que la había conmovido en sus cimientos. Sabía que para mejorarla era preciso iniciar su reorganización, su reestructuración. No quería significar con esto que había que volver los ojos hacia el pasado, ni tampoco que había que dejar libertad a cada hombre para que criticase a su entero gusto todo lo existente, todas las instituciones; situación que entrañaba la anarquía más completa. El punto de partida tenía que ser otro. Tenía que encontrarse un conjunto de proposiciones que descansase en la demostración y en la verificación, para que así permitiese la previsión y la organización de los grupos. Había que hacer, en una palabra, la ciencia de lo social. A ella correspondería la tarea de proporcionar el poder necesario para unir y guiar las inteligencias. La fe y la confianza en un futuro mejor se asentarían, por lo tanto, en el conocimiento adquirido por la investigación de los hechos sociales.

Sin embargo, la ciencia de lo social - sociología como la llama- 
rá Comte, con un neologismo de híbrida mezcla, pero cuyo uso posterior lo justifica plenamente- no puede construirse en el vacío. Debe descansar sobre el edificio sólido de las demás ciencias para que no sea un simple conjunto de afirmaciones arbitrarias. Pero, a su vez, las demás ciencias han de tener en vista el conocimiento de lo social si es que no quieren convertirse en vagas e inconsistentes críticas de los fenómenos; en una especie de ocio ingenioso. El hombre ha de tener como tarea conocer la naturaleza para someterla al servicio de sus fines, tal como ya lo había intuido Bacon. El hombre sólo alcanzará la fe en la organización social siempre que ésta descanse en el saber acerca del juego de las leyes que la rigen. He ahí algo posible y tangible, algo que está al alcance del investigador, pues se asienta sobre la verificación; sobre la demostración.

Y nuevamente el problema de la realidad. No es que Comte lo formule en una pregunta de hecho, fáctica, aun cuando toda su laboración filosófica la lleva implícita. Piénsese en el esfuerzo que despliega por mostrar que el conocimiento humano ha seguido la marcha de un progreso que comenzó buscando una realidad mística y avanzó hasta llegar a descubrir la realidad que es captación psicológica de los fenómenos. Es la conocida "ley de los tres estados". Un comienzo oscuro y lejano en que la humanidad intenta el conocimiento de las cosas en función de lo absoluto. Es la utilización del principio de causalidad llevado al través de analogías antropomórficas que pretenden inquirir en la substancia última. Junto a esta explicación que subraya la inquietud intelectual de aquella época, está también el desarrollo de la sociedad. En esta etapa, la teológica, habrían aparecido las castas sacerdotales y como una consecuencia, el militarismo. Clero y ejército habrían sido las instituciones que colocaron a la sociedad en la senda de la organización y de la estructuración.

Después de esta etapa... la anarquía. Interviene la razón criticando en forma demoledora. Es la destrucción de los cimientos forjados en la fase anterior. Es el despertar de la inteligencia que irrumpe violenta a través y sobre la creencia. Es el caos. Pero de las ruinas 
ha de surgir lo nuevo con el apuntar hacia metas diferentes. Los hechos se explican ahora por fuerzas abstractas. Otra vez el principio de causalidad. Si algo cambia o deviene, es porque hay fuerzas ocultas en los objetos mismos. Hay que conocerlas, esto es, hay que saber por qué ocurren los hechos. Como ya no se pueden atribuir al capricho siempre cambiante de los dioses, tienen que asignarse a los impulsos trascendențes que están en aquéllos. La regularidad advertida en el acontecer y que se debió a la interpretación teológica, impele al hombre a mudar de método para explicarlo. Paralelamente al cambio en la interpretación de lo dado se desarrolla una transformación en la organización de la vida social. La estructura religiosa de la sociedad se quiebra. Reyes y nobles asisten a la destrucción de los fundamentos que sustentaban sus prerrogativas. $\mathrm{El}$ individuo, espectador de este naufragio, se convierte en juez del bien y del mal al advertir que los principios aceptados son inoperantes. Pierde la fe en lo estatuido. Se vislumbra el comenzar de un nuevo camino hacia la búsqueda de la verdad. Así, este período denominado metafísico, pasa a servir de intermediario entre el estado teológico y el que ha de venir. La actitud de los pensadores de esta etapa ha servido para abrir la puerta al pensamiento laico-racional.

Finalmente el triunfo completo de la razón; el dominio de la inteligencia; la emancipación total del hombre. Atrás ha quedado la inútil indagación de los "por qué" sean ellos religiosos o metafísicos. A la zaga están las amarras que, o ataban el pensar a creencias religiosas o le constreñían a buscar la intimidad de substancias trascendentes e incognoscibles. Es el brotar de lo positivo. El hombre ha llegado al convencimiento que sólo puede desprender las leyes de los fenómenos tal como ellos se presentan en el espíritu. No deberá, pues, apartarse de aquello que el espíritu coge, esto es, en último término, los objetos en sus relaciones invariables de sucesión y de similitud. La ciencia es conocimiento de hechos. Pero no de hechos aislados, solitarios, ni es tampoco el registro estadístico de datos; razón por la cual, Comte, no puede ser tildado de empirista. Ciencia es la busca y el descubrimiento de las leyes. Mas si bien es 
cierto que sólo hay un saber: el que se basa en el conocimiento de las leyes y que sirve para hacer previsiones válidas, las relaciones que se han desprendido de los hechos y que han sido controladas no pierden por eso su valor relativo. Esta posición ya había sido adoptada por Leonardo y por Galileo, quienes siglos antes habían tenido la pretensión de alcanzar un punto de vista abarcador por el examen de la dependencia de los objetos entre sí, obtenido por la observación de los hechos.

Las leyes no pueden ser tomadas como algo definitivo, como algo absoluto, como pioposiciones últimas capaces de explicar la realidad. Son simplemente hipótesis de trabajo que han sido confirmadas por la observación, pero cuya validez es solamente aproximativa. Esta dependerá siempre de la efectividad que alcancen las aplicaciones de aquéllas. No tiene, por tanto, sentido buscar explicaciones causales al acontecer físico.

Así concebida la realidad, como fenómenos dados en la mente, no pasa a ser otra cosa que aquello que es captado por el espíritu. Aquello que, casi en forma pasiva, es consciente, vale decir, un darse cuenta en el sentido de tener ciencia. Con esto se reduce la realidad a fenómeno de conciencia. Todo lo que de ella se pueda saber o conocer es conocimiento de fenómenos existentes en la conciencia. El acento se coloca en el mundo dado como algo psicológico. Comte se desentiende definitivamente de la teoría o creencia en los dos mundos. Su posición, que podría señalarse con cierto rigor como sensualismo, trae como consecuencia lógica la negación de la posibilidad de cualquier conocimiento de lo absoluto, de toda indagación de tipo metafísico. Si sólo existe lo que es un contenido de conciencia, no puede haber nada que sea en el sentido de lo metafísico.

Esta misma posición implica una segunda consecuencia. Si únicamente hay conocimiento de lo que es dado, de aquello de lo cual se tiene conciencia, de lo que, en último término, es fenómeno mental, ha de haber una unidad en las ciencias particulares. Una unidad que conduce de lo que se llama físico hasta lo que se denomina social. Esta unidad no sólo descansa en el psicologismo inconsciente 
de Comte, sino también en el método que se ha de emplear para lograr el descubrimiento de la verdad.

Hay en la historia del pensamiento humano, en tanto es inquirir de la verdad, una relación extraña entre método y realidad. Podría parecer que la realidad, sea ella fenoménica o absoluta, sea ideal o valorativa, fuese la que determinase el método que se ha de emplear para conocerla. Sin embargo, no es así. En múltiples ocasiones es el método el que delimita y clarifica al objeto, en el sentido de que sólo se conoce hasta donde el método lo permite. Piénsese, por ejemplo, que el saber del mundo circundante sólo pasó a constituir una ciencia en el momento en que se le aplicó el método experimental. Téngase presente también cómo, dentro del terreno de la etnología, se hace posible la comprensión de la evolución de las culturas en cuanto se las enfoca como unidades sociales y se las observa en sus productos tal cual ellos florecen como manifestación de la trama de valores que las anima. Método significa empero poseer una posición previa en la mente. Es un ponerse en camino sabiendo que el camino existe ya o es posible. Presupone una idea anterior o hipótesis que defina lo que se va a estudiar, objeto al cual postula como existente. $\mathrm{Y}$ así surge el hecho curioso que el dato, lo dado, lo que se va a investigar y que, por lo tanto, se desconoce, ya es dado previamente a título problemático en el espíritu de quien lo va a conocer. Puede acaso objetarse que con el progreso de las ciencias se va avanzando, junto con una mayor profundización en la indagación de los datos - lo que implica una serie de problemas que han de ser resueltos en relación con la unidad sistemática dentro de la cual se encuentran encadenados-, a un descubrimiento de nuevos hechos, es decir, de nuevos sectores de la realidad, de nuevos problemas que generalmente exceden a los puntos de vista previamente adoptados. Esta objeción puede ser analizada desde dos puntos de vista. En primer término hay que dejar establecido que el descubrimiento de los hechos o fenómenos inexplicados y que representan nuevos sectores que han de interpretarse, han sido descubiertos en función de la idea o de la dirección que germinó en la mente del investigador. A 
pesar de que parece innecesario acudir a ejemplos, puesto que la historia de las ciencias y de la filosofía los ofrece en abundancia, es conveniente $\mathrm{y}$ es útil referirse a la mudanza a la cual se asiste en el instante en el cual los pensadores del Renacimiento primero, y Galileo, Kepler y Newton después, adoptan, como punto de partida de la ciencia, la investigación de los hechos mismos, frente a la suposición de que la verdad no está dada y que es necesario descubrirla. Y cómo se resuelven posteriormente los problemas que se plantean en la mecánica en función de los conceptos y de las leyes de Newton. Sin embargo, cuando surgen los problemas en torno a los fenómenos de la electricidad, es necesario acudir a nuevos conceptos que permiten forjar un sistema dentro del cual encuentran solución. En segundo término, los fenómenos inexplicados, cualesquiera que ellos sean dentro de la realidad fenoménica sólo son nuevos para el investigador, estaban produciéndose constantemente. Si no habían aflorado al campo de las observaciones, ello se debía, desde luego, a la carencia de un punto de partida y a una dirección orientadora que pusiese en acción procedimientos apropiados para la indagación propiamente científica. Esto determina, a su vez, la ausencia de técnicas operatorias adecuadas para llevar a cabo la investigación. Esta situación es válida naturalmente para el estudio de los héchos propios de la convivencia humana.

Comte, con visión genial, va a aprovechar y a canalizar las ideas y suposiciones ya elaboradas que iluminaban el sector de lo social y que, en forma de pensamiento político-filosófico, se venían desarrollando en el siglo XVIII y a comienzos del siglo XIX. A base de ellas delimita lo que la nueva ciencia ha de estudiar. Y, al mismo tiempo que fija el objeto de la sociología, establece que la investigación de los hechos sociales se ha de realizar de acuerdo con los métodos que emplean las demás ciencias. El paso necesario para que se desarrollase la sociología como ciencia positiva estaba dado.

Así la sociología nacía como ciencia positiva descansando sobre dos fundamentos: por una parte constituía una unidad con el resto de las ciencias particulares, no en el sentido de que supusiese la exis- 
tencia de leyes únicas y generales que explicasen el acontecer, sino en cuanto los resultados de las unas son imposibles sin que los principios y el avance de las otras les hubiese proporcionado el material adecuado para poder iniciar el examen de sus objetos. Cabe recordar, al respecto, como tantas veces se ha hecho en la historia de la filosofía, que apoyándose en este punto de vista, le corresponde a Comte el privilegio de haber logrado establecer una clasificación de las ciencias que descansa sobre leyes l6gicas.

La segunda condición para que una ciencia sea efectivamente positiva es el método. Considera que el saber sólo puede surgir, hacerse en el caso que emplee el cálculo y la experiencia. Es la negación de premisas a priori. Es la negación de lucubraciones que se asienten en el juego vano de la imaginación y que, en el mejor de los casos, conducen a nada. La sociología, por esta razón, ciencia que había de alcanzar la plenitud de la etapa positiva, tenía que servirse también de la observación, del cálculo y de la experiencia.

Del amplio sistema sintetizador y creador de Comte han quedado guiando el pensamiento humano después de cien años de su muerte bien pocas ideas directrices. Es el sino del hombre. Los deseos y anhelos de forjar algo grande y definitivo se rompen a poco de caminar. Pero no es nunca una pérdida cabal. No todo se destruye en un aniquilamiento definitivo. Las ideas se mantienen como luces creadoras, mientras el relámpago de la genialidad y de la novedad que encierran alumbra el campo de la investigación. Mientras sean fecundas para sugerir puntos de vista que ofrezcan soluciones interesantes para el inquieto espíritu humano y, en la medida, en que las circunstancias históricas no proporcionen nuevas perspectivas. Después no son sino hitos que, en el camino del pensamiento, indican cambios o crisis, comienzos o términos.

Muchas de las concepciones del padre del positivismo han sido superadas. Sin embargo, las proyecciones de la obra de Comte se manifiestan tanto en el terreno de las ciencias como en el de la filosofía. En las ciencias es innegable que el positivismo se ha impuesto como método. En la física, en la química, en las ciencias en general, 
no sólo se ha conservado el positivismo como método, sino que se le considera, y en este sentido ha sido desarrollado, como el único procedimiento operante para avanzar en la investigación de los hechos o fenómenos. Desde el punto de vista filosófico, como sistema, ha originado la corriente neopositivista entre cuyos representantes se pueden contar, entre muchos otros, a von Schlick, a Carnap, Reichenbach. Pero positivismó en el sentido estrictamente filosófico comtiano no existe. Los sistemas filosóficos son, como lo creía Bergson, intuiciones geniales. Dentro del campo de esta intuición, de este hacerse o adecuarse a la realidad poseen validez. Fuera de este ámbito se pierden y desaparecen. Pasan a ser objeto de la crítica y de la controversia. Lo que fue animación y savia fecunda para el filósofo, es después el reino de la objeción y de la discusión para los demás.

No se puede desconocer que todas las ciencias que enfocan los hechos en su función de descubrir leyes han tenido que adoptar la posición positiva. La ciencia es, en la actualidad -y se excluyen, por cierto por razones obvias, las ciencias denominadas culturales-, ciencia de hechos, ciencia de lo dado. Esto significa que eluden, como lo quería Comte, toda interpretación racional a priori, toda fabulación inconsistente. Dado quiere decir lo objetivo, lo que se enfrenta $u$ opone al sujeto cognoscente. En consecuencia, si se pretende conocerlo, habrá que prescindir de lo que, siendo exclusivamente subjetivo, no contribuya, en el sujeto, a aprehender racionalmente lo que es relación o condición propia de los objetos. Intereses, deseos, gustos o imaginación deben ceder su lugar, en la conciencia del investigador, a aquello que se impone desde el objeto. En este sentido la oposición objeto-sujeto significa, para el sujeto cognocente, más bien pasividad, más bien un abrirse a las características o notas que se ofrecen en el objeto. Significa evitar toda creación arbitraria que surja en la mente del investigador y que no tenga en vista el conocimiento del objeto como tal.

También se ha esclarecido el ámbito científico con la delimitación que hiciera respecto a la metafísica y a lo teológico, en cuanto niega toda relación causal entre los fenómenos y las fuerzas o causas 
trascendentes. Cierto es que otros pensadores como Sexto el Empírico, como Hume, como Galileo, o como Kepler y otros ya se habían preocupado de este problema. Sin embargo, es Augusto Comte quien, por primera vez, lo destacó en un intento histórico, al hacerlo objeto del análisis y del examen crítico al través de la ley de los tres estados. No rechaza, desde luego, el valor que la religión y la metafísica han tenido en la ordenación de lo social, ni tampoco en la pretensión que tuvieron de dar una explicación plausible al mundo, ni tampoco como el camino que condujo a la ciencia positiva. Lo que niega es que, la ciencia como explicación de los hechos, pueda aceptar la presencia o existencia de causas trascendentes, de causas ocultas. Recuérdese que Comte sólo acepta un mundo: el mundo de lo dado. No hay un tal segundo mundo. Huelga, por lo tanto, una explicación que descanse en un segundo mundo no existente. Aquello que de ninguna manera pueda ser percibido, que no pueda ser objeto de la experiencia no puede entrar en el campo del conocimiento científico.

En el ámbito de la microfísica la posición de Comte se ha mantenido en plena vigencia con investigadores como Heisenberg, Jordan, etc., quienes restan toda importancia a la búsqueda de causas físicas para explicar el acontecer en el núcleo. La causalidad física estaría de más según estos pensadores. Conocida es la ley de la indeterminación a la cual se acude para interpretar el suceder dentro del mundo del átomo, pues parece que dentro de él no rigiese el determinismo especialmente en lo que se refiere a los así llamados "mesones". La brevísima existencia temporal de éstos y las dificultades de las técnicas de observación dentro de lo infinitivamente pequeño han hecho imposible el descubrimiento de relaciones causales. Es absolutamente imposible en el presente determinar, a la vez, la situación y la velocidad de ellos. De aquí que los investigadores nombrados y algunos filósofos, entre los cuales conviene citar a A. Wenzel, estiman que las leyes sólo rigen el acontecer del mundo macrofísico. Más todavía, suponen que estas leyes son de tipo estadístico, las que sólo indicarían un conocimiento incompleto del sis- 
tema al cual se refieren y que estarán de más en cuanto se conozca el detalle. Algo análogo sucede con la teoría de los quanta. Mediante ella se puede determinar la probabilidad en que se desprenderá una partícula de un átomo de radio dentro de una unidad de tiempo, pero no existe la posibilidad de predeterminar el tiempo exacto en que tal hecho se ha de presentar. Predomina, pues, dentro del campo científico que tiene que ver con el mundo del átomo, la negación del principio de causalidad, posición que es netamente positivista. Esto no significa desconocer que hay también una oposición cerrada a este tipo de enfoque explicatorio de la realidad del núcleo por parte de numerosos investigadores como de Broglie, Heyde y el mismo autor de la teoría de los quantas, Planck. Después de cien años del fallecimiento de Comte, su idea de la negación de la explicación causal todavía se mantiene en algunos sectores de las ciencias.

Pero es en la sociología donde las líneas directrices impuestas por Comte se han mantenido vigentes. Esta ciencia ha tomado un ritmo acelerado aplicando al objeto social el método de estirpe positiva. Del sistema sociológico-filosófico, de las interpretaciones de un desarrollo rectilíneo de la humanidad pasando por las tres etapas no queda casi nada. Sin embargo, habrá que recordar siempre los fundamentos en los cuales se basó para indicar a los investigadores que vinieron, qué es lo que habían de hacer si es que querían hacer ciencia de lo social: sociología. 